\title{
Estimation of the Shelf Life of a Drug in Its Solid State. I. An Application of Lacey's Theory to a Kinetic Analysis of an Air Oxidation of Ascorbic Acid in Its Solid State
}

\author{
Sadao Hirota, Satoshi Osugi, Taizo Hayashi, \\ Shinichiro Kaga and Yasumitsu Takeya \\ Pharmaceutical Research Laboratory, Daiichi Seiyaku Co., Ltd.1)
}

(Received February 5, 1968)

\begin{abstract}
Lacey's theory, concerning a gas--solid reaction rate is applied to a stability study of a pharmaceutical solid. An accelerated air oxidation of ascorbic acid is analysed to predict its shelf life at room temperature as an example. The temperature dependence of the diffusion constant is found to be $48 \mathrm{kcal} / \mathrm{mole}$, and that of the chemical reaction rate, $26 \mathrm{kcal} / \mathrm{mole}$. The diffusion constant, and 2 nd order reaction rate constant at $25^{\circ}$ are estimated to be $1.6 \times 10^{-12} \mathrm{~cm}^{2} / \mathrm{hr}$, and $4.3 \times 10^{-4}$ liter $/ \mathrm{mole}-\mathrm{hr}$, respectively. The $1 \%$ degradation life of ascorbic acid in a disk of mannitol conglomerate containing $10 \%$ ascorbic acid is estimated to be about 200 years in the absence of moisture.
\end{abstract}

\section{Introduction}

The majority of drugs are in the solid state in their pure form at ordinary temperatures, and they are also often formulated in solid pharmaceuticals. A definite procedure to estimate the shelf life of a drug in the solid state is desired by formulators who are expected to guarantee the quality of the drug for a period of time. The problem has been solved to some extent for drugs in solutions, and an acceleration test based on kinetic theory is widely adopted as an effective means for an estimation of the aging of the solution. The prediction for stability of drugs in solid forms, however, has not been based on such good ground as yet. The aging of a drug in the solid state almost always involves a heterogeneous reaction which has much more complicated factors than a homogeneous reaction in solution. But the rapid progress in the mathematics of heterogeneous kinetics is considered to have reached a stage where it can be applied to practical pharmacy.

The present investigation is undertaken to propose a procedure for treating heat acceleration data to estimate the shelf life of a pharmaceutical solid when the aging is a simple gas-solid reaction. The air oxidation of solid ascorbic acid is studied in this aspect. The reaction is believed to be clearly a gas-solid reaction in the absence of moisture. Two factors are taken into consideration, the diffusion of oxygen into the solid, and the chemical reaction of oxygen and ascorbic acid. Both of these simultaneous processes are considered to control the reaction. In the stability studies of solid drugs, ${ }^{2-6)}$ it was assumed that absorbed water layers exist on the surface of drug particles, into which they dissolve, and decompose hydroly-

1) Location: Narihiva, Sumidaku, Tokyo.

2) L.J. Leeson, "Decomposition of Aspirin in the Solid State," Ph. D. Dissertation, Graduate School Library of the Univ. of Michigan, 1957.

3) L.J. Leeson and A.M. Mattocks, J. Pharm. Sci., 47, 329 (1958).

4) I. Lippmann, "Stability of Aspirin in the presence of Amphetamine salts," Ph. D. Dissertation, Graduate School Library of the Univ. of Michigan, 1959.

5) I. Lippmann, A.M. Mattocks, Am. Pharm. Assoc. Preprint papers Dll, 1962, p. 11, through C.A., 60, $1544(1964)$.

6) S. Osugi, S. Shirota, T. Hayashi, S. Kuga and Y. Takeya. The 22nd annual meeting of the Pharm. Assoc. of Japan, Preprint Papers, 1966, p. 188.

7) J. Crank, "The Mathematics of Diffusion," Clarendon press, Oxford, 1956, p. 117. 
tically as in ordinary saturated solutions. The absorbed water molecules were assumed to have the ordinary properties of solvent and reactant. Very little work has been carried out on gas-solid reactions between a drug and water vapor, so far as is known to the authors. Even when the stability against moisture is studied, kinetic discussions neglecting the gassolid reaction between a drug and water vapor may be incomplete.

In recent years, the interest in gas-solid reactions has increased in various industrial fields, partly because of wider commercial application of this type of reaction, and partly because of improved technological and mathematical treatments, including electronic computers, for analysing the reactions.

Some excellent work has been carried out in the field of gas-solid reactions, but most workers have correlated their kinetic and mass transfer data by empirical or semiempirical means, usually assuming that one of the above two mechanisms is the controlling factor. Diffusion of reactant gas through product layer is the mechanism most commonly assumed. For example, physical diffusion with a moving boundary is solved for a typical gas-solid reaction, that of metal tarnishing.?)

The diffusion of reactant gas through the product layer was assumed to be a slow process, while a chemical reaction at the unreacted solid surface is instantaneous.

In average pharmaceutical solid, however, packing is not so compact as in metal crystals, and they have many cracks and pores. The diffusion of gas molecules through pharmaceutical solids, then, is not a slow process as in metals. A chemical reaction, on the otherhand, is not always a rapid process, for most drugs are prepared in as stable a form as possible. Thus, gas-solid reactions in the pharmaceutical field must be considered to be controlled both by diffusion, and chemical reaction, simultaneously.

Lacey $^{8)}$ presented a new model for a gas-solid reaction based on the assumption that in the general case of both the rate of diffusion and chemical reaction governing the over-all rate of absorption, no gas-solid interface exists, and a reaction zone is substituted for this interface. The model allows for reactant gas to diffuse past a point in the solid where reactant solid particles still exist. It allows then for a concentration gradient of both solid reactant and gaseous reactant within the solid. Thus, our condition can be introduced from the same stand point as that of the Lacey.

Conditions, adopted in Lacey's theory, meet the situation of practical pharmacy much more closely than those of previous theories. Here, an outline of his theory is introduced briefly.

\section{Theoretical}

Assumption a; a solid in contact with a gas containing a gaseous reactant, reacts irreversibly with the solid according to

$$
A \text { (gas) }+v B \text { (solid) } \longrightarrow \text { Product(solid) }
$$

Assumption b; the reactant gas can diffuse in the solid, where it is immobilized by a second-order reaction, first-order with respect to both the gas and the solid.

Assumption c; the diffusivity of the gas within the solid is constant for all time and concentration.

Lacey solved the following simultaneous partial differential equations,

$$
\begin{aligned}
& \frac{\partial A}{\partial t}=D \frac{\partial^{2} A}{\partial x^{2}}-k A B \\
& \frac{\partial B}{\partial t}=-v k A B
\end{aligned}
$$

8) D.T. Lacey, J.H. Bowen and K.S. Basden, Ind. Eng. Chem., Fundamentals, 4, 275 (1965). 
with the boundary conditions,

$$
\begin{array}{ll}
A(0, t)=A_{i} & A(x, 0)=0 \\
B(0,0)=B_{\boldsymbol{o} i} & \\
A(\infty, t)=0 & B(\infty, t)=B_{o i}
\end{array}
$$

to obtain the numerical solution, Fig. 1, for different ratios of reactants, $Q=v A_{i} \mid B_{o i}$.

Lacey's theory can be employed effectively to calculate the two parameters, those of chemical reaction and diffusion, through the following procedure:

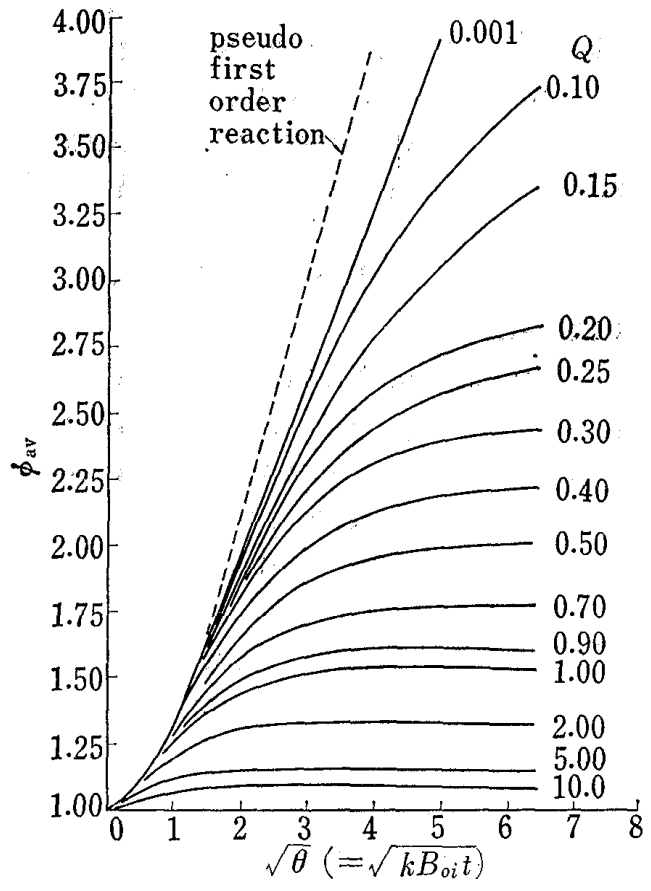

Fig. 1. Ratio of Average Rate of Absorption Due to Diffusion and Chemical Reaction to that Due to Diffusion Alone, $\phi_{\text {av }}$, as a Function of Dimensionless Time, $\theta$, for Different Values of $\nu A_{i} / B_{\boldsymbol{0} i}$. (cited from Fig. 3 of the Lacey's Paper. ${ }^{8)}$ )

Let $M_{t}=$ amount of gas absorbed at time $t$ by a diffusion accompanied by a chemical reaction. The amount of gas absorbed by physical diffusion alone, $M_{t}{ }^{\prime}$, is given by $\mathrm{Crank}^{6}$ )

$$
M^{\prime}{ }_{t}=2 C_{o}(\boldsymbol{D} t / \pi)^{1 / 2}
$$

The ratio of the two, $M_{t} / M_{t}{ }^{\prime}$, is $\phi_{\mathrm{av}}$ according to Lacey's definition

$$
\phi_{\mathrm{av}}=M_{t} / \mathrm{M}^{\prime} \mathrm{t}=M_{t} / 2 C_{\boldsymbol{o}}(\boldsymbol{D} t / \pi)^{1 / 2}
$$

where $\boldsymbol{D}$ is diffusion constant.

As $\phi_{\mathrm{av}}=1$ in any case at $t=0$; (the effect of chemical reaction does not appear at the very beginning), extrapolating $M_{t} / t^{1 / 2}$ to time zero will give the value of $2 C_{o}(\boldsymbol{D} / \pi)^{1 / 2}$ from which $\boldsymbol{D}$ is calculated. Introducing this value in equation (3), $\phi_{\mathrm{av}}$ is obtained for any time. It is then plotted against $t^{1 / 2}$. The resulting diagram is analogous to Fig. 1, in which $\phi_{\mathrm{av}}$ is plotted against $\theta^{1 / 2}=\left(k B_{o i} t\right)^{1 / 2}, k$ being the rate constant of the chemical reaction, and $B_{o i}$ the the molarity of solid reactant at the interface. By comparing the above defined dimensionless time, $\theta$, from Fig. 1, and the real time $t$ for the same values of $\phi_{\mathrm{av}}$, one can calculate the rate constant $k$. It is also possible to determine an accurate value of $A_{i}$, the molarity of the gas reactant in the solid phase at the interface, from the experimental asymptotic value of $\phi_{\mathrm{av}}$, as described later.

\section{Experimental}

Ascorbic acid in a mannitol conglomerate is studied. The oxidation of ascorbic acid in its solid state is reported to be accelerated by the presence of moisture. In order to simplify the experimental conditions, the oxidation was performed in the absence of moisture.

1. Materials-Ascorbic acid $\left(\mathrm{mp} 190^{\circ}\right)$ and mannitol $\left(\mathrm{mp} 168^{\circ}\right)$ are thoroughly dried in a vacuum silica gel desiccator for more than $24 \mathrm{hr}$. Remaining moisture is determined by a Shimazu Moisture Meter to be less than $0.1 \%$. Ninety gram of mannitol is put in a beaker and heated in an oil bath to $170^{\circ}$ until melting. Ten gram of ascorbic acid is dissolved into it. A clear melted mixture is quickly cooled to congeal, and the conglomerate is finely pulverized to pass J.P. VII Standard sieve No. 7 (200 mesh).

2. Determination of the Particle Size Distribution of the Material Powder- The above powder is suspended in ethyl oleate and its size distribution is analysed by a Hitachi Photo Scanning Particle Size Analyser. Fig. 2 shows the result. As a more detailed size distribution of the finer portion of the powder is needed, the analysis is repeated using normal heptane which has lower density and viscosity than ethyl oleate. $0.5 \%$ Span 80 (oil soluble non-ionic surface active agent) is added as the dispersing agent. The 


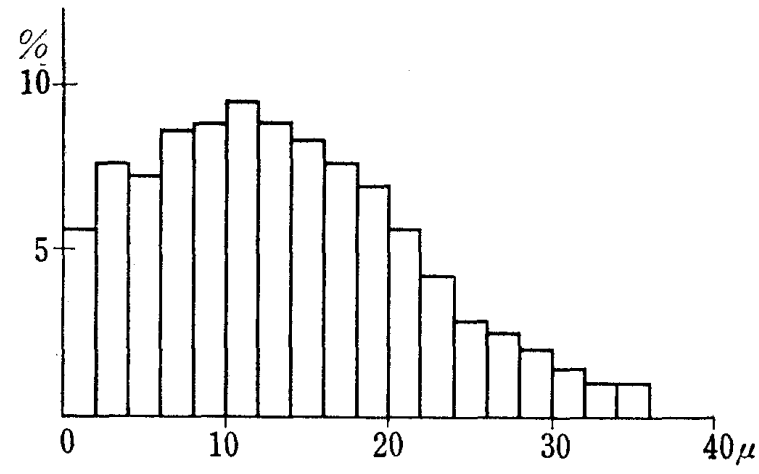

Fig. 2. Particle Size Distribution of Material Powder by an Hitachi Photo Scanning Particle Size Analyzer (PSA-2)

suspending liquid: ethyl oleate $(60 \mathrm{cps})$

(Microscopic observation does not detect particles larger than $30 \mu$.)

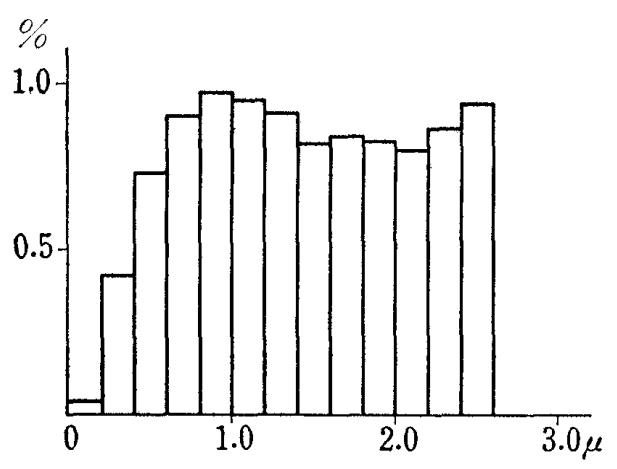

Fig. 3. Close-up Size Distribution of the Finer Portion of the Material Powder

suspending liquid: $\mathrm{N}$-heptane containing $0.5 \%$ Span 80.

Photo scanning data were analysed ass uming that the proportion of fine particles smaller than $3.0 \mu$ is $10 \%$ of the total weight of particles.

analysis of the obtained autograph is performed on the basis that the proportion of fine particles less than $3.0 \mu$ is $10 \%$ of the total weight of particles. The resulting particle size distribution is shown in Fig. 3 .

3. Compression of the Material Powder- $-0.3-0.4 \mathrm{~g}$ of the material powder is compressed by a $\mathrm{KBr}-$ tabletting machine for an infrared spectrometer (Nihon Bunkoh). The die is evacuated to $20 \mathrm{mmHg}$ and the powder compressed at 7 tons for five minutes by an oil press, and a disk $20 \mathrm{~mm}$ in diameter and $0.64-$ $0.78 \mathrm{~mm}$ thick is obtained. The change in the porosity with the punch pressure showed that the packing is closest. The obtained disk is an opaque solid, and has the appearance of compact porcelain.

4. Elevated Temperature Storage Test-Oil baths at $135^{\circ}, 128^{\circ}$ and $120^{\circ}$, and water baths at $95^{\circ}$, $80^{\circ}$ and $60^{\circ}$ are maintained at each temperature within $\pm 0.2^{\circ}$. Sample disks are suspended on the holder, and inserted in a test tube of $2.5 \mathrm{~cm}$ diameter and $20 \mathrm{~cm}$ length with an air inlet pipe at the bottom and an outlet pipe at the side. An air stream of volume velocity 3 liter $/ \mathrm{min}$ (linear velocity $10 \mathrm{~cm} / \mathrm{sec}$ ) from a diaphragm pump is passed through the test tube, which is immersed into the above described bath.

With this stream velocity, the oxygen concentration on the disk surface is considered to be the same as that in the atmosphere as follows:

Material transfer coefficient $k_{f}$, at this velocity, is $2 \mathrm{~cm} / \mathrm{sec}$ according to Ranz \& Marshall's equation, ${ }^{9)}$ which relates $k_{f}$ to fluid stream. Oxygen absorption by the disk is, at most, of the order of $10^{-8} \mathrm{~mole} / \mathrm{cm}^{2}-\mathrm{sec}$ as described later, while the oxygen concentration drop in the boundary film of air is of the order of $\Delta c=10^{-8} / k_{f}=5$ $\times 10^{-9} \mathrm{~mole} / \mathrm{ml}$, which is negligible compared

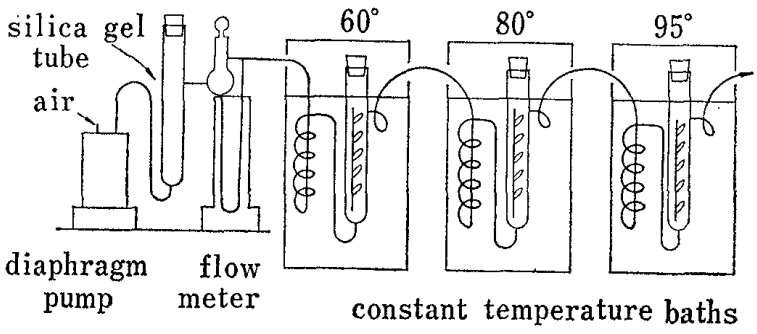

Fig. 4. The Arrangement of the Heating Baths with the atmospheric oxygen concentration of $8 \times 10^{-6} \mathrm{~mole} / \mathrm{ml}$.

Initial temperature change in the test tube after its immersion in the bath was measured and found that even with preheating of the inlet air, the predetermined temperature is not attained within 10 minutes. It takes almost half an hour before the complete disk attains the desired temperature. The influence of the time lag in the temperature for the first hour of the reaction can not be neglected.

5. Demoisturization of the Inlet Air and the Determination of Humidity in the Test Tube-A capillary condensation is possible at humidity much less than the critical humidity. The relative humidity at which the capillary condensation begins in a pore with $1 \mathrm{~m} \mu$ diameter is calculated to be $30 \%$ from Kelvin's equation. ${ }^{10)}$ The maintenance of the relative humidity of the inlet air below $10 \%$ will be sufficient to avoid formation of condensed water in a pore. The relative humidity of the air after passage through a drying tube filled with $100 \mathrm{~g}$ of dry silica gel at a flow rate of $3 \mathrm{liter} / \mathrm{min}$ was found to be $\mathbf{1 5 - 2 0 \%}$, using an "Ace Humidity Meter" (Yamato Kagaku Kikai) at $25^{\circ}$. The relative humidity of this air is estimated to be $1.0-1.3 \%$ at $80^{\circ}$, and a still lower value at $95^{\circ}$ or higher. Thus, there is no need to be anxious about the presence of liquid water in the sample, even if capillary condensation is taken in account.

6. Determination of Ascorbic Acid-To the sample disk, accurately weighed $\left(W_{1} g\right)$, stored in the above described high temperature tube with an air stream, $5 \mathrm{ml}$ of meta phosphoric acid-acetic acid mixture (an

9) W.E. Ranz and W.R. Marshall, Jr., Chem. Eng. Prog., 48, 141 (1952).

10) A.E. Alexander and P. Johnson, "Colloid Science," Oxford, Clarendon Press, 1950, p. 607. 
aqueous solution containing $6 \%$ meta phosphoric acid and $16 \%$ acetic acid) is added and dissolved in water in a $100 \mathrm{ml}$ volumetric flask. $10 \mathrm{ml}$ aliquote is titrated with $0.025 \%$ aqueous solution of 2,6 -dichlorophenolindophenol (containing $0.025 \%$ sodium bicarbonate) $\left(T_{1} \mathrm{ml}\right)$. A sample disk, which has not undergone heatstorage $\left(W_{2} g\right)$, is treated in the same way and titrated $\left(T_{2} \mathrm{ml}\right)$. The residual ratio of ascorbic acid is calculated by the following equation.

$$
R=\left(\boldsymbol{C}_{o}-x\right) / \boldsymbol{C}_{0}=T_{1} W_{2} / T_{2} W_{1}
$$

where $C_{0}$ is initial ascorbic acid concentration, and $x$ the product concentration.

The total error in measurement is considered to be about $\pm 0.2 \%$, and reproducibility $2-3 \%$. One of sources of fluctuation seems to be an irregular compactness in the disk.

\section{Results}

The residual ratio of ascorbic acid after storage at each temperature is shown in Table I, and plotted in Fig. 5 and 6 . The product concentration in the table is defined by the following equation:

$$
x=C_{o}(1-R)
$$

TABLE I. Change in the Residual Ratio of Ascorbic Acid

\begin{tabular}{|c|c|c|c|}
\hline $\begin{array}{l}\text { Temperature } \\
T\left({ }^{\circ} \mathrm{C}\right)\end{array}$ & $\begin{array}{l}\text { Time } \\
t(\mathrm{hr})\end{array}$ & $\begin{array}{l}\text { Residual V.C. } \\
\quad R \text { (ratio) }\end{array}$ & $\begin{array}{c}\text { Product concentration }{ }^{a)} \\
x \text { (mole/liter) }\end{array}$ \\
\hline 135 & $\begin{array}{l}1 \\
3 \\
5 \\
7\end{array}$ & $\begin{array}{l}0.737 \\
0.510 \\
0.410 \\
0.296\end{array}$ & $\begin{array}{l}0.1991 \\
0.3710 \\
0.4447 \\
0.5345\end{array}$ \\
\hline 128 & $\begin{array}{r}1 \\
3 \\
5 \\
10\end{array}$ & $\begin{array}{l}0.973 \\
0.878 \\
0.766 \\
0.610\end{array}$ & $\begin{array}{l}0.0203 \\
0.0923 \\
0.1779 \\
0.2956\end{array}$ \\
\hline 120 & $\begin{array}{r}1 \\
3 \\
7 \\
12\end{array}$ & $\begin{array}{l}0.989 \\
0.949 \\
0.871 \\
0.761\end{array}$ & $\begin{array}{l}0.0081 \\
0.0390 \\
0.0978 \\
0.1816\end{array}$ \\
\hline 95 & $\begin{array}{r}7 \\
31 \\
96 \\
172 \\
263 \\
351\end{array}$ & $\begin{array}{l}0.985 \\
0.963 \\
0.883 \\
0.826 \\
0.767 \\
0.734\end{array}$ & $\begin{array}{l}0.0114 \\
0.0280 \\
0.0889 \\
0.132 \\
0.177 \\
0.202\end{array}$ \\
\hline 80 & $\begin{array}{l}405 \\
896\end{array}$ & $\begin{array}{l}0.976 \\
0.944\end{array}$ & $\begin{array}{l}0.0182 \\
0.0425\end{array}$ \\
\hline
\end{tabular}
and Oxide Concentration with Time

a) defined by equation (5)

\section{Discussions}

\section{Analysis of the Results by a Modification of Lacey's Procedure}

Some modifications to Lacey's procedure are necessary in order to apply his theory to the present study. It takes at least ten to fifteen minutes to raise the temperature inside the tube to the predetermined temperature.

Due to this time lag in the temperature, data, accurate enough to extrapolate $M_{t} / t^{1 / 2}$ toward $t=0$, cannot be obtained. 


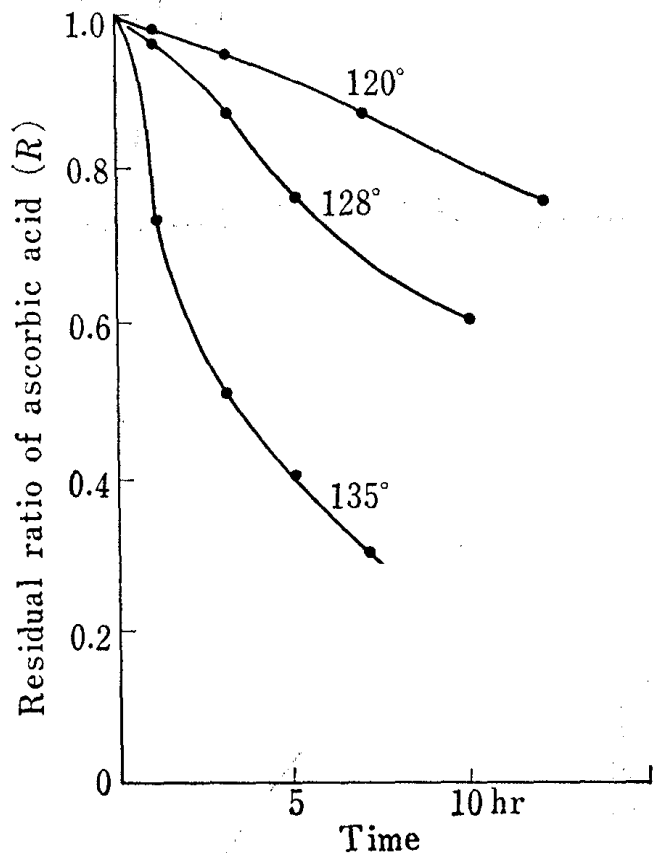

Fig. 5. Air Oxidative Degradation of Ascorbic Acid in a Mannitol Conglomerate Containing 10\% Ascorbic Acid

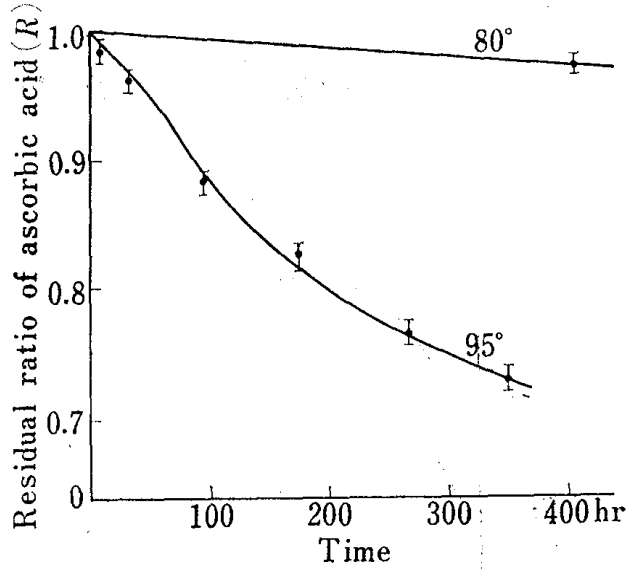

Fig. 6. Air Oxidative Degradation of Ascorbic Acid in a Mannitol Conglomerate Containing 10\% Ascorbic Acid

However, through the following procedure, a rough estimation of $D$ and $k$, in Lacey's theory, is possible. The value of $A_{i}$ must be estimated. When the gas stream arround the solid is rapid, and the gas absorption rate is slow compared with its supply rate, the concentration drop in the gas boundary film is small.

The reactant gas concentration just "on" the surface, ${ }^{11)} C_{i}$, which is believed to be higher than the bulk gas concentration $C_{A}$, due to the surface adsorption, will no doubt be related to $A_{i}$, the reactant gas molarity just "below" the surface, 12) which is believed to be lower than $C_{i}$.

Thus, both $C_{\boldsymbol{A}}$ and $A_{i}$ are generally lower than $C_{i}$. Although $C_{A}$ and $A_{i}$ are not necessarily equal, there may not be much difference between the two.

The expedience, taken in the following analysis, is based upon the assumption

$$
C_{A}=A_{i}
$$

$Q$ is determined by (7) for an equimolecular reaction,

$$
Q=A_{i} / B_{o i}=C_{o} / C_{0}=C_{A} / C_{0}
$$

Now that $Q$ is thus obtained, it is not necessary to depend on an inaccurate extra-

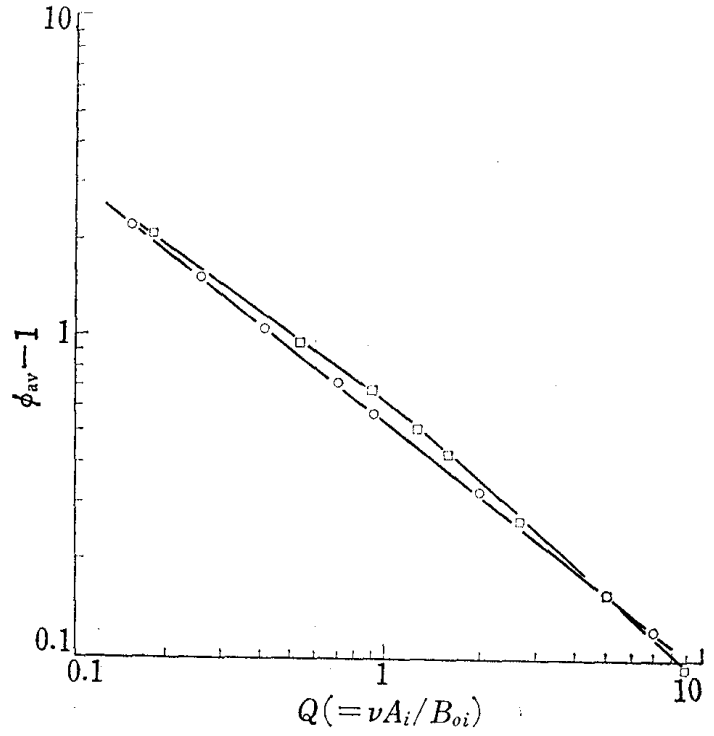

Fig. 7. Asymptotic Value of Average Rate Ratio, $\phi_{a v}$, plotted as a Function of $v A_{i} / B_{0 i}$, for both Numerical and Analytical Solutions. (cited from Fig. 5 of the Lacey's Paper. ${ }^{8)}$ )

computed results

11) The concentration of the reactant gas molecules in the gas boundary film at the interface.

12) The concentration of the reactant gas molecules in the solid at the interface. 
polation to $t=0$. The asymptotic value of $\phi_{\mathrm{av}}$, then, is given either by Fig. 7 , or by the Sherwood-Pigford equation. ${ }^{13)}$

$$
\phi_{\mathrm{av} . \text { asymp. }}=\sqrt{\pi / 2 Q}
$$

According to (6), (7) and (8), $A_{i}=8 \times 10^{-3}$ mole/liter, $Q=1.4 \times 10^{-2}$ and $\phi_{\text {av.asy mp. }}=10$. Then $\boldsymbol{D}$ is given by

$$
\dot{\phi}_{\mathrm{av} . \text { asymp. }}=\left(M_{t} / t^{1 / 2}\right)_{\text {asy mp. }} / 2 C_{\boldsymbol{o}}(\boldsymbol{D} / \pi)^{1 / 2}=10
$$

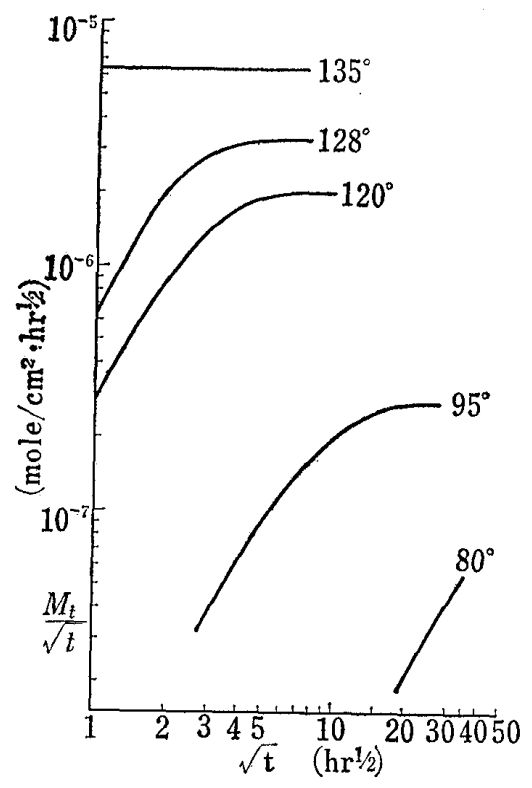

Fig. 8. $M_{t} / t^{1 / 2}$, Obtained in Table II, versus Root of Time

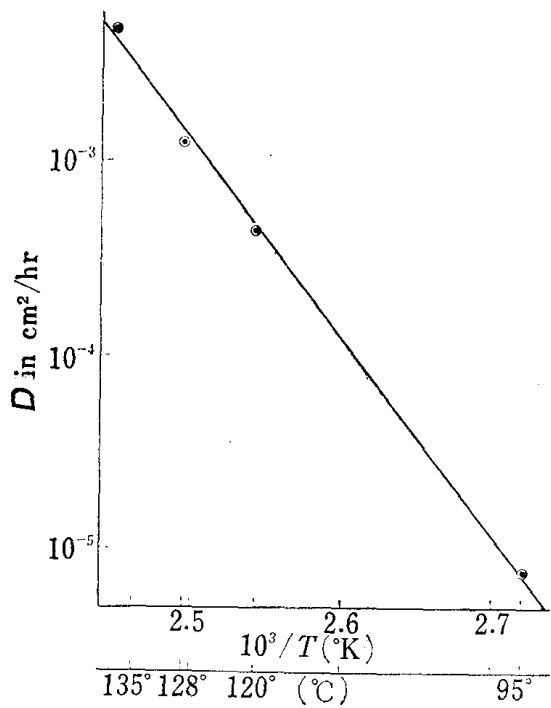

Fig. 9. Temperature Dependence of the Diffusion Constant, $\boldsymbol{D}$

$\log D=23.4-10500 / T, \Delta E=48 \mathrm{kcal} / \mathrm{mole}$

TABLE II. Calculation of $M_{t} / t^{1 / 2}$

\begin{tabular}{ccccc}
\hline $\begin{array}{c}\text { Temperature } \\
T^{\circ}(\mathrm{C})\end{array}$ & $\begin{array}{c}\text { Time } \\
(\mathrm{hr})\end{array}$ & $\begin{array}{c}\text { Root } \\
\left(\mathrm{hr} \mathbf{1}^{1 / 2}\right)\end{array}$ & $\begin{array}{c}M_{t} \\
\left(\mathrm{~mole} / \mathrm{cm}^{2}\right)\end{array}$ & $\begin{array}{c}M_{t} / \mathrm{t}^{1 / 2} / 2 \\
\left(\mathrm{~mole} / \mathrm{cm}^{2} / \mathrm{hr}^{1 / 2}\right)\end{array}$ \\
\hline 135 & 1 & 1.00 & $0.64 \times 10^{-5}$ & $6.4 \times 10^{-6}$ \\
& 3 & 1.73 & $1.19 \times 10^{-5}$ & $6.9 \times 10^{-6}$ \\
& 5 & 2.24 & $1.42 \times 10^{-5}$ & $6.4 \times 10^{-6}$ \\
128 & 7 & 2.65 & $1.71 \times 10^{-5}$ & $6.5 \times 10^{-6}$ \\
& 1 & 1.00 & $0.65 \times 10^{-6}$ & $6.5 \times 10^{-7}$ \\
& 3 & 1.73 & $2.96 \times 10^{-6}$ & $1.7 \times 10^{-6}$ \\
& 5 & 2.24 & $5.7 \times 10^{-6}$ & $2.5 \times 10^{-5}$ \\
120 & 10 & 3.16 & $9.5 \times 10^{-6}$ & $3.0 \times 10^{-5}$ \\
& 1 & 1.00 & $0.26 \times 10^{-6}$ & $2.6 \times 10^{-7}$ \\
& 3 & 1.73 & $1.25 \times 10^{-6}$ & $7.2 \times 10^{-7}$ \\
& 7 & 2.65 & $3.13 \times 10^{-6}$ & $1.18 \times 10^{-6}$ \\
95 & 12 & 3.46 & $5.81 \times 10^{-6}$ & $1.68 \times 10^{-6}$ \\
& 7 & 2.65 & $0.365 \times 10^{-6}$ & $1.38 \times 10^{-7}$ \\
& 31 & 5.57 & $0.897 \times 10^{-6}$ & $1.61 \times 10^{-7}$ \\
& 96 & 9.80 & $2.85 \times 10^{-6}$ & $2.9 \times 10^{-7}$ \\
& 172 & 13.1 & $4.23 \times 10^{-6}$ & $3.2 \times 10^{-7}$ \\
& 263 & 16.2 & $5.67 \times 10^{-6}$ & $3.5 \times 10^{-7}$ \\
& 351 & 18.7 & $6.47 \times 10^{-6}$ & $3.5 \times 10^{-7}$ \\
& 405 & 20.1 & $0.583 \times 10^{-6}$ & $2.9 \times 10^{-8}$ \\
& 896 & 29.9 & $1.36 \times 10^{-6}$ & $4.6 \times 10^{-8}$ \\
& & & &
\end{tabular}

13) T.K. Sherwood and R.L. Pigford, “Absorption and Extraction,” McGraw-Hill, New York, 1952, p. 332. 
TABLE III. Calculation of Diffusion Constant $D$

\begin{tabular}{cccc}
\hline $\begin{array}{c}\text { Temperature } \\
\left({ }^{\circ} \mathrm{C}\right)\end{array}$ & $\begin{array}{c}\left(M_{t} / t^{1 / 2}\right)_{\mathrm{asy} \mathrm{mp}} \\
\left(\mathrm{mole}_{\mathrm{cm}} \mathrm{cm}^{2}-\mathrm{hr}^{1 / 2}\right)\end{array}$ & $\begin{array}{c}2 C_{o}(\boldsymbol{D} / \pi)^{1 / 2} \\
\left(\mathrm{~mole}_{\mathrm{cm}} \mathrm{cm}^{2}-\mathrm{hr}^{1 / 2}\right)\end{array}$ & $\begin{array}{c}\boldsymbol{D} \\
\left(\mathrm{cm}^{2} / \mathrm{hr}^{\prime}\right)\end{array}$ \\
\hline 135 & $6.4 \times 10^{-6}$ & $6.4 \times 10^{-7}$ & $4.88 \times 10^{-3}$ \\
128 & $3.3 \times 10^{-6}$ & $3.3 \times 10^{-7}$ & $1.23 \times 10^{-3}$ \\
120 & $2.0 \times 10^{-6}$ & $2.0 \times 10^{-7}$ & $0.44 \times 10^{-3}$ \\
95 & $2.8 \times 10^{-7}$ & $2.8 \times 10^{-8}$ & $0.0078 \times 10^{-3}$ \\
\hline
\end{tabular}

$\left(M_{t} \mid t^{1 / 2}\right)_{\text {asy mp. }}$ is obtained graphically from the $M_{t} \mid t^{1 / 2}$ versus $t^{1 / 2}$ plot (Fig. 8), where $M_{t} / t^{1 / 2}$ is calculated using the experimental $x$ in Table I, and is listed in Table II. The $2 C_{o}(\boldsymbol{D} / \pi)^{1 / 2}$ and $\boldsymbol{D}$ values thus obtained are listed in Table III. $\log \boldsymbol{D}$ is plotted against $1 / T$, and a straight line is obtained as in Fig. 9.

Nernst-Einstein's equation ${ }^{14)}$ is applied to this result, and an empirical equation (10) is obtained.

$$
\log \boldsymbol{D}=23.4-10500 / T
$$

The activation energy concerning diffusion is calculated to be $48 \mathrm{kcal} /$ mole. $\phi_{\mathrm{av}}$ is found as in Table IV by introducing $2 C_{0}(\boldsymbol{D} / \pi)^{1 / 2}$ in Table III, and $M_{t} / t^{1 / 2}$ in Table II, into equation (3). $\phi_{\mathrm{av}}$ is plotted against $t^{1 / 2}$ in Fig. 10.

By taking $t^{1 / 2}$ in Fig. 10, and $\theta^{1 / 2}$ in Fig. 1 , that give the same value of $\phi_{\mathrm{av}}, k$ is calculated by

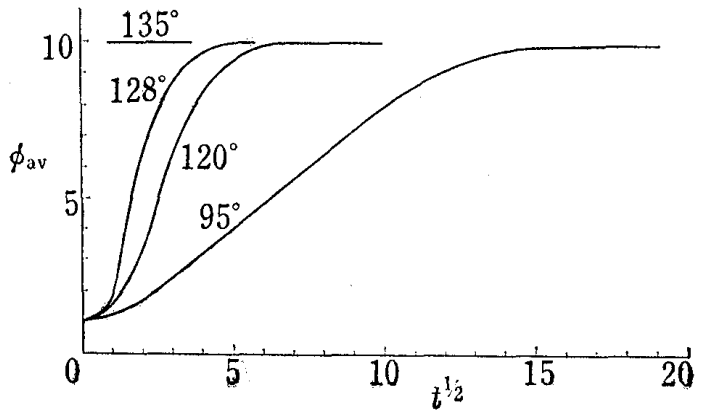

Fig. 10. $\phi_{\mathrm{av}}$, in Table 5, versus Root of Time, $t^{1 / 2}$

$$
k=\left(\theta^{1 / 2} / t^{1 / 2}\right)^{2} / C_{o}
$$

TABLE N. Calculation of $\phi_{\mathrm{a}}$

\begin{tabular}{cccc}
\hline $\begin{array}{c}\text { Temperature } \\
\left({ }^{\circ} \mathrm{C}\right)\end{array}$ & $\begin{array}{c}\text { Time, } t \\
(\mathrm{hr})\end{array}$ & $\begin{array}{c}\text { Root of } t \\
\left(\mathrm{hr}^{1} / 2\right)\end{array}$ & $\dot{\phi}_{\text {av }}$ \\
\hline 135 & 1 & 1.00 & 10.0 \\
& 3 & 1.73 & 10.0 \\
& 5 & 2.24 & 10.0 \\
& 7 & 2.65 & 10.0 \\
128 & 1 & 1.00 & 2.03 \\
& 3 & 1.73 & 5.32 \\
& 5 & 2.24 & 7.95 \\
& 10 & 3.16 & 9.35 \\
& 1 & 1.00 & 1.33 \\
& 3 & 1.73 & 3.75 \\
& 7 & 2.65 & 6.17 \\
& 12 & 3.47 & 8.75 \\
95 & 7 & 2.64 & 3.97 \\
& 31 & 5.57 & 3.76 \\
& 96 & 9.80 & 8.35 \\
& 172 & 13.1 & 9.25 \\
& 263 & 16.2 & 10.0 \\
& 351 & 18.7 & 9.86 \\
& & &
\end{tabular}

14) A. Einstein, Ann. Physik., 17, 549 (1905) (Cited in W. Jost, "Diffusion in Solids, Liquids, Gases," Academic Press, New York, 1960, p. 142.) 
TABLE V. Calculation of Chemical Reaction Rate Constant, $k$

\begin{tabular}{|c|c|c|c|c|c|c|c|}
\hline $\begin{array}{l}\text { Temperature } \\
\left({ }^{\circ} \mathrm{C}\right)\end{array}$ & $\phi_{\mathrm{av}}$ & $\theta 1 / 2$ & $t^{1 / 2}$ & $\theta^{1 / 2} / t^{1} / 2$ & & $\stackrel{k}{(\text { liter } / \mathrm{mole} / \mathrm{hr})}$ & $\begin{array}{c}\not k C_{0} \\
\left(h r^{-1}\right)\end{array}$ \\
\hline 128 & $\begin{array}{l}9.0 \\
7.0 \\
5.0\end{array}$ & $\begin{array}{r}14.0 \\
9.8 \\
6.6\end{array}$ & $\begin{array}{l}3.1 \\
2.0 \\
1.5\end{array}$ & $\begin{array}{l}4.5 \\
4.9 \\
4.4\end{array}$ & 4.6 & 37 & 0.29 \\
\hline 120 & $\begin{array}{l}9.0 \\
7.0 \\
5.0\end{array}$ & $\begin{array}{r}14.0 \\
9.8 \\
6.6\end{array}$ & $\begin{array}{l}4.4 \\
3.1 \\
2.3\end{array}$ & $\begin{array}{l}3.2 \\
3.2 \\
2.9\end{array}$ & 3.1 & 17 & 0.14 \\
\hline 95 & $\begin{array}{l}9.0 \\
7.0 \\
5.0\end{array}$ & $\begin{array}{r}14.0 \\
9.8 \\
6.6\end{array}$ & $\begin{array}{r}12.0 \\
8.4 \\
6.0\end{array}$ & $\begin{array}{l}1.17 \\
1.17 \\
1.10\end{array}$ & 1.15 & 2.3 & 0.018 \\
\hline
\end{tabular}

In order to apply Arrhenius' equation, $\log k C_{o}$ must be plotted against $1 / T$, for $k C_{o}$ of a second order reaction corresponds to $k$ of a first order reaction. Although the plots obtained were not straight lines and data for several more temperatures are needed, the following empirical equation can be obtained by taking the average,

$$
\begin{aligned}
\log k C_{0}= & 13.34-5.600 / T \\
& \left(k C_{0} \text { in } \mathrm{hr}^{-1} \quad T \text { in }{ }^{\circ} \mathrm{K}\right)
\end{aligned}
$$

The activation energy of the chemical reaction is calculated to be about $26 \mathrm{kcal} / \mathrm{mole}$.

\section{Estimation of Shelf Life of Ascorbic Acid at Room Temperature}

Using equations (10) and (12), $D$ and $k$ at $25^{\circ}$ are estimated to be $1.6 \times 10^{-12} \mathrm{~cm}^{2} / \mathrm{hr}$ and $4.3 \times 10^{-4}$ liter/mole-hr, respectively. As $t$ is converted into $\theta$ by

$$
\theta=k C_{0} t=2.46 \times 10^{-4} t
$$

$\phi_{\mathrm{a} v}$ at any time $t$ is given by the $Q=0.014$ line in Fig. $1 . \quad M_{t}$ is given by

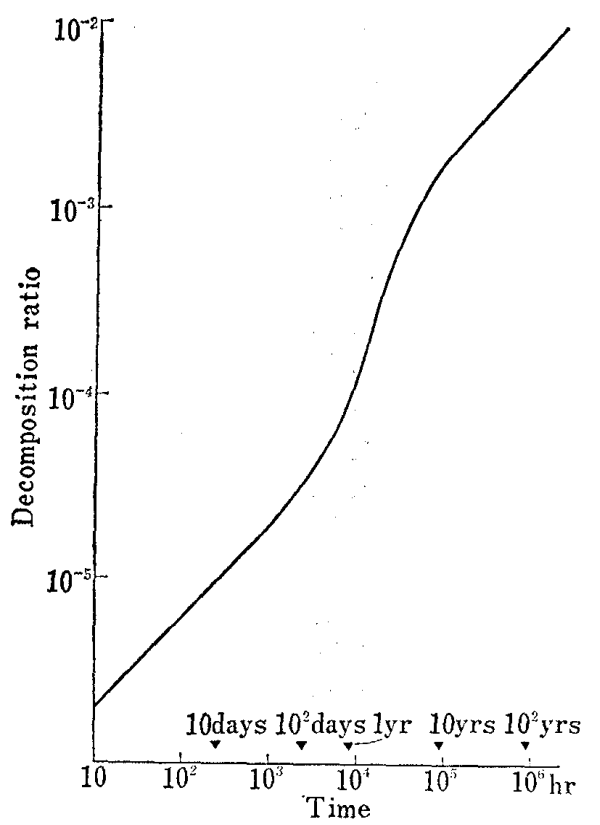

Fig. 11. Prediction of Air Oxidation of Ascorbic Adid in the Disc of Mannitol Conglomerate Containing 10\% Ascorbic Acid at $25^{\circ}$

$$
M_{t}=2 C_{o}(D / \pi)^{1 / 2} \phi_{\mathrm{qv}} t^{1 / 2}=1.14 \times 10^{-8} \phi_{\mathrm{av}} t^{1 / 2}
$$

and the decomposition ratio is calculated by (15)

$$
M_{t} / C_{0}=M_{t} / 0.567
$$

These calculations are listed in Table VI, and the estimated decomposition curve at $25^{\circ}$ is obtained as Fig. 11, from which the $1 \%$ degradation life of ascorbic acid in a disc of mannitol conglomerate containing $10 \%$ ascorbic acid is estimated to be about 200 years in the absence of moisture.

\section{Conclusion}

One of the difficulties met by the application of Lacey's theory to the stability test is the contradiction between the theoretical requirements and the limitations of experimental techniques. In order to determine the diffusion factor, $2 C_{o}(\boldsymbol{D} / \pi)^{1 / 2}, M_{t} / t^{1 / 2}$ must be extrapolated toward $t=0$. However, as is expected from Fig. 1, the change in $M_{t} t^{1 / 2}$ with $t$ (or $t^{1 / 2}$ ) 
TABLE VI. Calculation of Decompsoiton Ratio of Ascorbic Acid in a Disc of Mannitol Conglomerate containing $10 \%$ Ascorbic Acid at $25^{\circ}$

\begin{tabular}{cccccc}
\hline$t(\mathrm{hr})$ & \multicolumn{1}{c}{$\theta$} & $\phi_{\mathrm{av}}$ & $M_{t} t t^{1 / 2}$ & $M_{t}$ & $M_{t} / C_{o}$ \\
\hline 10 & $2.46 \times 10^{-3}$ & 1.00 & $1.14 \times 10^{-8}$ & $3.60 \times 10^{-8}$ & $6.35 \times 10^{-8}$ \\
$10^{2}$ & $2.46 \times 10^{-2}$ & 1.00 & $1.14 \times 10^{-8}$ & $1.14 \times 10^{-7}$ & $2.01 \times 10^{-7}$ \\
$10^{3}$ & $2.46 \times 10^{-1}$ & 1.05 & $1.18 \times 10^{-8}$ & $3.72 \times 10^{-7}$ & $6.56 \times 10^{-7}$ \\
$10^{4}$ & 2.46 & 2.25 & $2.44 \times 10^{-8}$ & $2.44 \times 10^{-6}$ & $4.30 \times 10^{-6}$ \\
$2 \times 10^{4}$ & 4.92 & 4.00 & $4.35 \times 10^{-8}$ & $6.15 \times 10^{-6}$ & $1.08 \times 10^{-5}$ \\
$4 \times 10^{4}$ & 9.85 & 7.20 & $7.77 \times 10^{-8}$ & $1.55 \times 10^{-5}$ & $2.74 \times 10^{-5}$ \\
$6 \times 10^{4}$ & $1.48 \times 10$ & 9.10 & $9.85 \times 10^{-8}$ & $2.41 \times 10^{-5}$ & $4.25 \times 10^{-5}$ \\
$8 \times 10^{4}$ & $1.97 \times 10$ & 9.90 & $1.07 \times 10^{-7}$ & $3.02 \times 10^{-5}$ & $5.33 \times 10^{-5}$ \\
$10^{5}$ & $2.46 \times 10$ & 10.00 & $1.08 \times 10^{-7}$ & $3.41 \times 10^{-5}$ & $6.00 \times 10^{-5}$ \\
$10^{6}$ & $2.46 \times 10^{2}$ & 10.00 & $1.08 \times 10^{-7}$ & $1.08 \times 10^{-4}$ & $1.90 \times 10^{-4}$
\end{tabular}

is not linear near $t=0$. Therefore, precise data for $M_{t}$ at the very beginning is required. $M_{t}$ at the beginning ( $\simeq \simeq 0$ ), however, contains a large experimental error because of the time lag in sample temperature, and time error. Even if a rapid determination of $M_{t}$ is possible, it is meaningless if one considers the time lag in the temperature.

To overcome this difficulty, the determination of the diffusion factor from data taken at the beginning had to be given up. Instead, an expedience, such as equation (6), had to be taken in the present investigation as is described in the last section.

No analytical solution (rate equation) has been given for the basic equation in Lacey's theory, but only a numerical solution, Fig. 1, is given. If a rate equation is given which relates the experimental reaction curve $(R$ versus $t)$ to the diffusion and reaction parameters, a more convenient and accurate prediction of the shelf life of a solid drug could be made.

Acknowledgement The authors wish to express their deep gratitude to Prof. Takao Kwan of Tokyo University and his co-workers, especially to Mr. Haruhiko Yamamoto, for their helpful criticism and suggestions throughout this work. We are grateful to Prof. A.M. Mattocks of The University of Michigan, and Dr. L.J. Leeson and Dr. I. Lippmann for their discussion and advice. We also thank the Daiichi Seiyaku Co. Ltd., especially Dr. Masao Shimizu, for their kind encouragement. 